\title{
Downscale fermentation for xylooligosaccharides production by recombinant Bacillus subtilis 3610
}

\author{
Cláudia Amorim $^{\mathrm{a}}$, Sara C. Silvério ${ }^{\mathrm{a}}$, Raquel F.S. Gonçalves ${ }^{\mathrm{a}}$, Ana C. Pinheiro ${ }^{\mathrm{a}, \mathrm{b}}$, Soraia Silva ${ }^{\mathrm{c}}$, \\ Elisabete Coelho ${ }^{c}$, Manuel A. Coimbra ${ }^{c}$, Kristala L.J. Prather ${ }^{\mathrm{d}}$, Lígia R. Rodrigues ${ }^{\mathrm{a}, *}$ \\ ${ }^{\text {a } C E B-C e n t r e ~ o f ~ B i o l o g i c a l ~ E n g i n e e r i n g, ~ U n i v e r s i d a d e ~ d o ~ M i n h o, ~ C a m p u s ~ d e ~ G u a l t a r, ~ 4710-057 ~ B r a g a, ~ P o r t u g a l ~}$ \\ ${ }^{\mathrm{b}}$ Instituto de Biologia Experimental e Tecnológica, Avenida da República, Quinta-do-Marquês, Estação Agronómica Nacional, Apartado 12, 2781-901 Oeiras, Portugal \\ ' QOPNA, Departamento de Química, Universidade de Aveiro, 3810-193 Aveiro, Portugal \\ ${ }^{\mathrm{d}}$ Department of Chemical Engineering, Massachusetts Institute of Technology, 77 Massachusetts Ave, Cambridge, MA 02139, United States
}

\section{A R T I C L E I N F O}

\section{Keywords:}

Xylooligosaccharides

Bacillus subtilis

Prebiotic

Xylan

Xylanase

\begin{abstract}
A B S T R A C T
The global demand of prebiotics such as xylooligosaccharides (XOS) has been growing over the years, motivating the search for different production processes with increased efficiency. In this study, a cloned Bacillus subtilis 3610 , containing the xylanase gene xyn2 of Trichoderma reesei coupled with an endogenous secretion tag, was selected for XOS production through direct fermentation of beechwood xylan. A mixture of XOS with a degree of polymerization ranging from 4 to 6 was obtained, presenting high stability after a static in vitro digestion $(98.5 \pm 0.2 \%)$. The maximum production yield expressed as total XOS per amount of xylan $(306 \pm 4 \mathrm{mg} / \mathrm{g})$ was achieved after $8 \mathrm{~h}$ of fermentation operating under one-time impulse fed-batch. The optimal conditions found were $\mathrm{pH} 6.0$ and $42.5^{\circ} \mathrm{C}$, using $2.5 \mathrm{~g} / \mathrm{L}$ of initial concentration of xylan increased up to $5.0 \mathrm{~g} / \mathrm{L}$ at $3 \mathrm{~h}$. Xylopentaose was the major oligosaccharide produced, representing $47 \%$ of the total production yield.
\end{abstract}

\section{Introduction}

In the light of current health consciousness, the demand of prebiotic food ingredients has been growing, as consumers prefer natural therapeutics to prevent widespread diseases, such as from the cardiovascular system, gastrointestinal tract or oncology (Kaprelyants, Zhurlova, Shpyrko, \& Pozhitkova, 2017). GVR - Grand View Research Inc. (2016) estimates that global prebiotic market will worth 7.11 billion $\$$ by 2024. According to the updated definition, a prebiotic can be defined as "a substrate that is selectively utilized by host microorganisms conferring a health benefit" (Gibson et al., 2017). Xylooligosaccharides (XOS) are emerging prebiotics, presenting a remarkable potential as food ingredients due to their minimal recommended daily intake (1.4-2.8 g) (Finegold et al., 2014), heat and pH stability (Courtin, Swennen, Verjans, \& Delcour, 2009), organoleptic properties and multidimensional effects on human health and livestock (Aachary, Gobinath, Srinivasan, \& Prapulla, 2015). XOS were reported as able to stimulate the growth of bifidobacteria (Hsu, Liao, Chung, Hsieh, \& Chan, 2004) and to produce lactate in a higher extent than other oligosaccharides (Rycroft, Jones, Gibson, \& Rastall, 2001). In addition, these compounds are the only nutraceuticals that can be sourced from lignocellulosic biomass, such as agro-residues, which are an abundant and renewable resource (Cruz et al., 2018).

Chemically, XOS are oligosaccharides composed by $2-10$ residues of $(\beta 1 \rightarrow 4)$-linked xylose. The main chain of xylose can comprise several substituents, namely acetyl groups, glucuronic acid, methylated glucuronic acid, arabinose, and hexose residues, depending on the biomass origin and the production process (Coelho, Rocha, Moreira, Domingues, \& Coimbra, 2016). XOS are produced though the hydrolysis of xylan, which is the main constituent of hemicelluloses and the second most abundant carbohydrate in the lignocellulosic biomass (Bian et al., 2013). Particularly, they can be obtained by different hydrolytic methods including chemical, auto- hydrolysis, enzymatic hydrolysis, or a combination thereof (Carvalho, Neto, Silva, \& Pastore, 2013). Chemical and auto-hydrolytic methods may originate undesired by-products, including toxic compounds such as hydroxymethylfurfural and furfural (Bian et al., 2014).

Additionally, the use of chemicals together with extreme operational conditions require more robust and expensive equipment. Thus, the enzymatic process is generally preferred for XOS used in food (Kaprelyants et al., 2017), presenting higher efficiency and specificity towards the product, allowing the control of the degree of polymerization (DP) and to reduce the costs associated with the downstream process (Bian et al., 2014). Moreover, this process represents a

\footnotetext{
* Corresponding author.

E-mail addresses: lrmr@mit.edu, lrmr@deb.uminho.pt (L.R. Rodrigues).
} 
more environment-friendly approach, since it operates at milder conditions not requiring the use of noxious chemicals (Azelee et al., 2016). However, xylan is generally comprised in a xylan-lignin matrix structure present in the lignocellulosic biomass (Samanta et al., 2012). Thus, XOS are mainly produced by a two-step combination of different methods, including a first step of fractionation of the lignocellulosic material to obtain soluble xylan and then, its hydrolysis by xylanolytic enzymes (Carvalho et al., 2013). The low yields associated to the first step of extraction in addition to the cost of producing or purchasing commercially available xylanases, may compromise the economic viability of the production process (Reddy \& Krishnan, 2016a). Amorim et al. (2018) addressed this problem by showing the potential of Bacillus subtilis to produce XOS in a single-step fermentation for one specific residue application, namely using brewer spent grain (BSG) as raw material. In this work, it is proposed the study of XOS production by direct fermentation using a commercial xylan in order to have a more detailed insight on the process and microorganism metabolism, particularly in terms of biomass growth evaluation, which is not possible when a complex residue is used as raw material. This comprehensive study may allow designing different one-step strategies to overcome the main issues associated with XOS production from agro-residues, specifically mass transfer and inhibition by the substrate. Moreover, this study reports for the first time the downscale process applied in the context of XOS production by direct fermentation of beechwood xylan, a hardwood tree that generates highly abundant forest residues. This study is particularly focused on (a) finding the $B$. subtilis clone with the highest potential to produce XOS; (b) proving that the best fermentation time corresponds to the time at which the maximum amount of oligosaccharides is reached (with minimal concentration of monosaccharides); (c) determining the profile curves associated to xylan concentration, temperature, and $\mathrm{pH}$, which are three important process variables, as well as determining the biomass profile; (d) testing batch and fed-batch process modes of operation to produce XOS. The main challenge of this work is to test the hypothesis of direct fermentation of hardwood xylans using genetically modified microorganisms as an efficient alternative for XOS production.

\section{Experimental}

\subsection{Materials}

The chemical composition of the beechwood xylan used in this study was provided by the manufacturer (CAS: 9014-63-5, Lot 141202, Megazyme, Bray, Ireland), containing xylose (81.3\%), glucuronic acid $(13.0 \%)$, and other sugars $(5.7 \%)$, namely glucose, arabinose, galactose, rhamnose, and mannose. All chemicals, media and media components were of analytical grade obtained from Sigma-Aldrich Chemical Ltd., unless specified otherwise.

\subsection{Bacterial strains, pre-inoculum, and fermentation media}

Bacillus subtilis 3610 wild type (wt) and two clones, previously constructed (Amorim et al., 2018), were used: clone 1 containing the xylanase gene xyn2 (X69574.1 Genbank NCBI) from Trichoderma reesei and clone 2 containing a secretion tag endogenous to $B$. subtilis ( $>\operatorname{tr} \mid$ A0A0S2II12| Uniprot) coupled to xylanase N-terminus site.

To prepare the pre-inoculum, one colony of $B$. subtilis grown on LB agar plate overnight at $37^{\circ} \mathrm{C}$ was picked into $2 \mathrm{~mL}$ of LB medium (Difco, New Jersey, USA) and spectinomycin $(100 \mu \mathrm{g} / \mathrm{ml})$ was added when required for clones selection. The cells were then cultivated at $37^{\circ} \mathrm{C}$ and $250 \mathrm{rpm}$ during approximately $2 \mathrm{~h}$ until reaching $\mathrm{OD}_{600} \sim 1.0$. This starter culture was then diluted to $\mathrm{OD}_{600} \sim 0.020$ into the fermentation media. Fermentation medium consisted in a mixture of commercial beechwood xylan (Megazyme) in 2\% (v/v) of Vogel medium (Vogel, 1956), autoclaved at $121^{\circ} \mathrm{C}$ during $15 \mathrm{~min}$.

\subsection{Downscale fermentation of xylan by B. subtilis: optimization of process} variables and operation mode

The Biolector apparatus (m2p-labs, USA) was used for highthroughput fermentations in flower plates (MTP-48-B, m2p-labs, USA). For all fermentations, each plate well was filled up to a total of $1 \mathrm{~mL}$ of xylan solution in $2 \%(\mathrm{v} / \mathrm{v})$ of Vogel medium and inoculated as described in Section 2.2. The cells were cultivated during $24 \mathrm{~h}$ and samples were collected over time, centrifuged ( $3000 \mathrm{rpm}$ during $3 \mathrm{~min}$ ) and further analyzed (Section 2.7).

The performance of $B$. subtilis wt, clone 1 and clone 2 regarding the production of XOS were compared in batch conditions, using $10 \mathrm{~g} / \mathrm{L}$ of commercial beechwood xylan at $\mathrm{pH} 7.0,45^{\circ} \mathrm{C}$ and $950 \mathrm{rpm}$. The selected transformant was used for further optimization studies.

The individual effects of substrate concentration (1.25, 2.5, 5.0, 10, 15 and $20 \mathrm{~g} / \mathrm{L}), \mathrm{pH}(5.0,6.0,6.5,7.0$ and 8.0) and temperature (37.0, $40.0,42.5,45.0$ and $47.0^{\circ} \mathrm{C}$ ) were optimized in sequence by selecting the most favorable value of one parameter at each time.

The fed-batch operation mode by one-time impulse was also studied in order to test the hypothesis of substrate inhibition and also to further optimize the process. Two initial concentrations of xylan were tested $(2.5$ and $5.0 \mathrm{~g} / \mathrm{L})$ which were increased up to 5.0 and $7.5 \mathrm{~g} / \mathrm{L}$, respectively, by one impulse at different times (3, 5, 7 and $9 \mathrm{~h})$.

All fermentation assays were performed in duplicate and samples from the supernatant were collected, centrifuged and further analyzed in triplicate.

\subsection{Quantification of biomass growth}

The biomass growth obtained under optimal conditions in batch and fed-batch modes was accessed by cell counting using a Neubauer improved chamber. The samples were diluted in Vogel $2 \%(\mathrm{v} / \mathrm{v})$ medium and observed under an inverted microscope (Eclipse TS100, Nikon) coupled with a SPOT Insight fire camera that allowed to capture the cells using a total magnification of $400 \times$. The cells pictures were processed in Spot software 5.0 setting manual exposure at $25 \mathrm{~ms}$, 8 gain and $2 \times 2$ bin.

\subsection{Sugar analysis and enzymatic activity}

For all the fermentation assays, samples from the supernatant were collected, centrifuged and further analyzed. The DNS (3,5-dinitrosalicylic acid) method (Miller, 1959) was used as a screening qualitative technique to assess the total reducing sugars, RS (mg). The sugar production yield, $Y_{R S}(\mathrm{mg} / \mathrm{g})$, was defined as the ratio between RS $(\mathrm{mg})$ and the mass of xylan $(\mathrm{g})$ used in the fermentation. The enzymatic activity of endo-( $\beta 1 \rightarrow 4)$-xylanase was accessed using a soluble chromogenic substrate according to the supplier guidelines for azo-xylan from birchwood (S-AXBP, Megazyme, Bray, Ireland).

\subsection{XOS quantification}

The XOS produced under optimum conditions were directly quantified by HPLC (Section 2.9), after previous purification of the fermentative broth with activated charcoal (Section 2.8). During the HPLC analysis the produced XOS were separated and individually collected according to their DP for chemical characterization analysis (Section 2.9). The DP of the XOS was estimated by TLC, as described by Amorim, Silvério, and Rodrigues, (2019), and confirmed by HPLC (Section 2.9) and GC-MS (Section 2.10). The XOS yield, $Y_{X O S}(\mathrm{mg} / \mathrm{g}$ ) was defined as the ratio between the total concentration of XOS (mg) and the mass of xylan $(\mathrm{g})$ used in the fermentation.

\subsection{Mass balance in xylose equivalents}

For accurate comparison purposes, the process mass balance was 
performed in terms of xylose equivalents, $\mathrm{X}_{\mathrm{eq}}(\mathrm{mg})$, per gram of xylan used in the fermentation.

The composition of XOS, $Y_{\text {XOS Xeq }}(\mathrm{mg} / \mathrm{g})$, and the initial amount of xylan, $Y_{x y l a n}\left(\mathrm{mg} / \mathrm{g}\right.$ ), in $X_{\mathrm{eq}}$, was determined by HPLC (Section 2.9) after acid hydrolysis according to (National Renewable Energy Laboratory) protocols (NREL/TP-510-42618-42622-4218).

The microorganism uptake of xylose, $Y_{x u p}(\mathrm{mg} / \mathrm{g})$, was quantified by the difference between the $Y_{x y l a n}$ and the yield in xylose equivalents of the supernatant obtained after the fermentation, $\mathrm{Y}_{\mathrm{XS}}$. The free xylose yield, $Y_{x y l}(\mathrm{mg} / \mathrm{g})$ was defined as the ratio between the concentration of free xylose (mg) (Section 2.9) and the mass of xylan (g).

The residual xylan, $Y_{X R}(\mathrm{mg} / \mathrm{g})$, was determined as follow: $\mathrm{Y}_{\mathrm{XR}}(\mathrm{mg} /$ $g)=Y_{x y l a n}-\left(Y_{X s}+Y_{x u p}+Y_{x y l}\right)$.

\subsection{Partial purification of XOS produced by direct fermentation}

To minimize the salt interference in the HPLC analysis, XOS produced by fermentation of xylan under optimal conditions were treated with activated charcoal as described in Amorim et al. (2019). The supernatant was collected $(20 \mathrm{~mL})$, centrifuged and loaded onto $13 \mathrm{~g}$ of activated charcoal. After the adsorption step, the charcoal was washed with MiliQ water, followed by sugar desorption using a mixture of butanol, acetic acid and water $(2: 1: 1 \mathrm{v} / \mathrm{v} / \mathrm{v})$ as eluent. The collected eluent with sugars was evaporated to dryness and the samples were resuspended in water for further analysis (Sections 2.9 and 2.10).

\subsection{Sugars analysis by HPLC}

Two distinct HPLC methods were used, namely to quantify monosaccharides or oligosaccharides partially purified (Section 2.8). For monosaccharides quantification, an HPLC (Agilent Technologies, USA) fitted with RI and DAD detectors (Agilent Technologies, USA) and an Aminex HPX 87H column $(300 \mathrm{~mm} \times 7.8$; Biorad, USA) were used for quantification. A volume of $10 \mu \mathrm{L}$ of sugar sample was eluted using $5 \mathrm{mM} \mathrm{H}_{2} \mathrm{SO}_{4}$ as the mobile phase at a flow rate of $0.7 \mathrm{~mL} / \mathrm{min}$ and a temperature of $60^{\circ} \mathrm{C}$. Furfural and HMF concentrations were also determined by HPLC, using the DAD detector. For the oligosaccharides quantification, an HPLC (JASCO, Japan) fitted with RI detector (K-2300 Knauer, Germany) and a Prevail Carbohydrate column $(250 \mathrm{~mm} \times$ $4.6 \mathrm{~mm}$; Grace, USA) were used. A mixture of acetonitrile and water $68: 32(\mathrm{v} / \mathrm{v})$ was used as mobile phase at a flow rate of $0.9 \mathrm{~mL} / \mathrm{min}$, temperature of $30^{\circ} \mathrm{C}$ and $20 \mu \mathrm{L}$ injection volume. Pure XOS (X2-X6) were used as standards for the identification of the produced oligosaccharides DP.

\subsection{XOS characterization}

Partially methylated alditol acetates were obtained from XOS samples using $\mathrm{CH}_{3} \mathrm{I}$ as methylating reagent (Coelho et al., 2016) and analyzed by GC-MS, as described by Amorim et al. (2018). XOS DP was calculated as the relative amount of total xylose divided by the amount of terminally linked xylose, as xylose (Xyl) should not occur as branching residues. The ratio between the branching points in substituted Xyl residues $\left(\mathrm{Xyl}_{\text {subst }}\right)$ and the total amount of $\mathrm{Xyl}\left(\mathrm{Xyl}_{\text {total }}\right)$ : $\left[\mathrm{Xyl}_{\text {subst }} / \mathrm{Xyl}_{\text {total }}\right]$ was used to calculate the branching degree, where $\mathrm{Xyl}_{\text {subst }}$ is the sum of the amount of monosubstituted residues $(2,4-\mathrm{Xyl}$ $+3,4-\mathrm{Xyl})+$ twice the amount of disubstituted residues $(2,3,4-\mathrm{Xyl})$.

\subsection{In vitro gastrointestinal digestion}

The supernatant containing the mixture of XOS produced under optimal conditions was lyophilized and used to test its stability under a harmonized static in vitro digestion method as described by Minekus et al. (2014). Briefly, $5 \mathrm{~mL}$ of XOS samples were prepared and subsequently exposed to conditions simulating the mouth, stomach and small intestine. At the oral phase, the sample was mixed with simulated salivary fluid solution (SSF), $\mathrm{CaCl}_{2}\left(\mathrm{H}_{2} \mathrm{O}\right)_{2}$ (to obtain $1.5 \mathrm{mmol} / \mathrm{L}$ in the fluid) and purified water (at volume necessary to achieve $1 \mathrm{x}$ of concentration of SSF). The mixture was incubated at $37{ }^{\circ} \mathrm{C}$ in a shaking bath (B. BRAUN BIOTECH model CERTOMAT WR, Melsungen, Germany) under agitation at $120 \mathrm{rpm}$ during $2 \mathrm{~min}$. The gastric phase consisted in the addiction of simulated gastric fluid (SGF), porcine pepsin $\left(2000 \mathrm{U} / \mathrm{mL}\right.$ in the final mixture) and $\mathrm{CaCl}_{2}\left(\mathrm{H}_{2} \mathrm{O}\right)_{2}$ (to obtain $0.15 \mathrm{mmol} / \mathrm{L}$ in the fluid). The mixture was adjusted to $\mathrm{pH} 3.0$ through the addition of $\mathrm{HCl} 1 \mathrm{M}$. Purified water was added in order to achieve $1 \mathrm{x}$ concentration of SGF. The final mixture was incubated over $2 \mathrm{~h}$ at $37^{\circ} \mathrm{C}$ and under agitation at $120 \mathrm{rpm}$. The intestinal phase was simulated by the addiction of simulated intestinal fluid (SIF), porcine pancreatin $(100 \mathrm{U} / \mathrm{mL}$ in the final mixture), bile solution $(10 \mathrm{mmol} / \mathrm{L}$ in the final mixture) and $\mathrm{CaCl}_{2}\left(\mathrm{H}_{2} \mathrm{O}\right)_{2}$ (to obtain $0.6 \mathrm{mmol} / \mathrm{L}$ in the fluid) The mixture $\mathrm{pH}$ was adjusted to 7.0 by adding the necessary volume of $\mathrm{NaOH} 1 \mathrm{M}$ or $\mathrm{HCl} 1 \mathrm{M}$. Purified water was added in order to achieve $1 \mathrm{x}$ concentration of SIF. The final mixture was incubated during $2 \mathrm{~h}$ at $37^{\circ} \mathrm{C}$ under agitation at $120 \mathrm{rpm}$. Samples were collected after the in vitro digestion and the reaction was stopped by adding the enzyme inhibitor pefabloc $(1 \mathrm{mmol} / \mathrm{L})(10 \mu \mathrm{L}$ per $1 \mathrm{~mL}$ of sample). All samples were tested at least in triplicate.

\section{Results and discussion}

3.1. Optimization of the production of XOS by direct fermentation of xylan using the B. subtilis

\subsubsection{Evaluation of the transformants performance for the production of} XOS

The performance of the B. subtilis wild type (wt) as XOS producer by direct fermentation of xylan was compared with the clone 1 and clone 2 cultured in microbioreactor, using $10 \mathrm{~g} / \mathrm{L}$ of xylan at $\mathrm{pH} 6.0,45^{\circ} \mathrm{C}$ and $950 \mathrm{rpm}$ (Fig. 1). These operational conditions were defined based on previous literature reports (Amorim et al., 2018; Helianti et al., 2016; Irfan, Asghar, Nadeem, Nelofer, \& Syed, 2016).

All tested strains achieved the maximum value of $\mathrm{Y}_{\mathrm{RS}}, \mathrm{Y}_{\mathrm{RS} \text { max }}$, after $8 \mathrm{~h}$ of fermentation. Nonetheless, clone $2(127 \pm 8 \mathrm{mg} / \mathrm{g})$ presented higher $Y_{\text {RSmax }}$ values when compared to the wild type $(93 \pm 7 \mathrm{mg} / \mathrm{g})$, showing a statistically significant increase of $37 \%$ (t-student test, $\alpha=0.05$ ). Moreover, all the production curves obtained present similar profiles, which may indicate that the expression of the heterologous

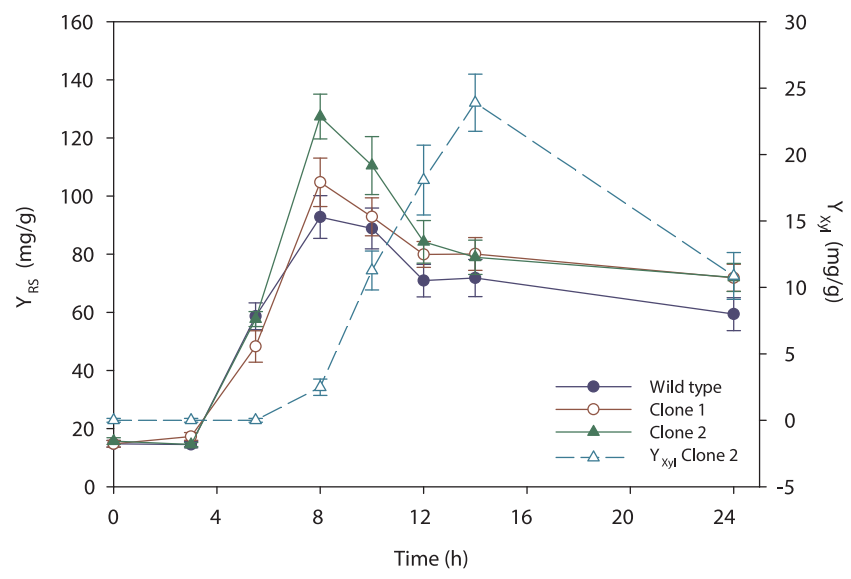

Fig. 1. Sugar production yield $\left(\mathrm{Y}_{\mathrm{RS}}\right)$ obtained for Bacillus subtilis 3610 wild type, Bacillus subtilis clone 1 (transformant containing the xylanase gene $x y n 2$ from Trichoderma reesei) and Bacillus subtilis clone 2 (transformant containing the xylanase gene $x y n 2$ from $T$. reesei coupled with a secretion tag endogenous to $B$. subtilis), and free xylose yield $\left(\mathrm{Y}_{\mathrm{xyl}}\right)$ obtained for $B$. subtilis clone 2 . The fermentations were performed in microbioreactor, using $10 \mathrm{~g} / \mathrm{L}$ of xylan in $2 \%$ (v/v) Vogel media at $\mathrm{pH} 6.0,45^{\circ} \mathrm{C}$ and $950 \mathrm{rpm}$. Results represent the average of three independent assays \pm standard deviation. 
xylanase did not impose a metabolic burden to the cells. Although being recognized as a high protein-secreting microorganism (Van Zyl, den Haan, \& la Grange, 2013), B. subtilis wt and clone 1 achieved similar $\mathrm{Y}_{\mathrm{RS} \max }$ and enzymatic activity values, suggesting that the secretion tag present in clone 2 possibly plays a significant role in the secretion of the heterologous xylanase, increasing its performance in terms of sugars production from xylan.

The free xylose yield, $Y_{x y l}$, was determined by HPLC (Fig. 1) for clone 2 . Interestingly, when $\mathrm{Y}_{\mathrm{RS} \max }$ was achieved $(8 \mathrm{~h})$, only low amounts of free xylose were present in the liquid media $\left(\mathrm{Y}_{\mathrm{xyl}}=3.5 \pm 0.6 \mathrm{mg} / \mathrm{g}\right)$, suggesting that the $\mathrm{Y}_{\mathrm{RSmax}}$ value is mainly represented by oligosaccharides. Thus, it seems that there is an optimal time around $8 \mathrm{~h}, \mathrm{t}_{\max }$, which corresponds to the time phase at which the oligosaccharides are accumulated, before starting to be degraded into xylose (maximum between 10 and $14 \mathrm{~h}$ ) (Fig. 1). The TLC analysis of the fermentation supernatant after $8 \mathrm{~h}$ of fermentation shows defined bands in the region of 4-, 5- and 6-DP XOS and a vestigial band is visible in the xylose region (Appendix A, Fig. A1 in Supplementary material).

The improvement of the clone 2 performance was also confirmed by xylanase activity analysis, presenting an increase of approximately $50 \%$ in the maximal activity at $12 \mathrm{~h}$ when compared to the wild type (data not shown). Based on these results, B. subtilis clone 2 was selected for further optimization studies (Section 3.1.2).

\subsubsection{Optimization of the initial $p H$, xylan concentration and temperature} for XOS production using the B. subtilis clone 2

Extracellular $\mathrm{pH}$, substrate concentration and temperature are process variables affecting significantly the growth of bacteria and enzyme production. These variables were separately studied in order to evaluate their individual effect on the XOS production by direct fermentation of xylan using clone 2 (Fig. 2).

The effect of the initial $\mathrm{pH}$ on the $\mathrm{Y}_{\mathrm{RS}}$ was studied at $45^{\circ} \mathrm{C}, 10.0 \mathrm{~g} / \mathrm{L}$ of xylan and $950 \mathrm{rpm}$, using different $\mathrm{pH}$, from $\mathrm{pH} 5.0$ up to 8.0 (Fig. 2A). The highest $Y_{R S m a x}(128 \pm 8 \mathrm{mg} / \mathrm{g})$ was achieved after $8 \mathrm{~h}$ of fermentation at $\mathrm{pH}$ 6.0, when as expected, the $\mathrm{Y}_{\mathrm{xyl}}$ was maintained at low levels $(3.3 \pm 0.8) \mathrm{mg} / \mathrm{g}$. In this sense, $\mathrm{pH} 6.0$ was selected for further studies, corresponding to the $\mathrm{pH}$ previously used to compare the transformants performance (Section 3.1.1).

The optimal $\mathrm{pH}$ for this process was possibly influenced by several phenomena, i.e. it was established as a function of the $\mathrm{pH}$ conditions more favorable for Bacillus growth, xylanase production and xylan solubility. In particular, $B$. subtilis growth in minimal medium is usually performed around pH 7.0 (Jaacks, Healy, Losick, \& Grossman, 1989), while the optimal $\mathrm{pH}$ for $B$. subtilis xylanase activity has been reported around pH 5.0-5.5 (Irfan et al., 2016; Milessi et al., 2015; Reddy \& Krishnan, 2016b), as well as for T. reesei xyn2 (Tenkanen, Puls, \& Potanen, 1992). Interestingly, the optimal $\mathrm{pH}$ for production of AXOS by direct fermentation of BSG with $B$. subtilis clone 2 was $\mathrm{pH} 7.0$ (Amorim et al., 2018). However, in that process the exposure of the carbohydrates present in the lignocellulosic biomass to the enzymes is improved by alkaline conditions (Maurelli, Ionata, La Cara, \& Morana, 2013).

The effect of the xylan concentration on $Y_{R S}$ was studied using different concentrations of xylan in $2 \%(\mathrm{v} / \mathrm{v})$ Vogel medium at $\mathrm{pH} 6.0$, $45^{\circ} \mathrm{C}$ and $950 \mathrm{rpm}$ (Fig. 2B). The $\mathrm{Y}_{\mathrm{RS} m a x}$ was achieved after $8 \mathrm{~h}$ of fermentation for all the concentrations tested.

For 2.5 and $5.0 \mathrm{~g} / \mathrm{L}$ of xylan, similar $\mathrm{Y}_{\mathrm{RS} m a x}$ values were obtained $(133 \pm 10$ and $133 \pm 8 \mathrm{mg} / \mathrm{g}$, respectively). However, for 2.5 and $1.25 \mathrm{~g} / \mathrm{L}$, the measured concentrations of sugars are close to the lowest sensitivity limit of the DNS method, which may also explain the higher error associated to the $Y_{R S}$ values, in particular associated to the $Y_{R S}$ values at $0 \mathrm{~h}$. On the other hand, concentrations of xylan higher than $5.0 \mathrm{~g} / \mathrm{L}$ had a negative impact on the $\mathrm{Y}_{\mathrm{RS} m a x}$, reducing significantly (tstudent test, $\alpha=0.05$ ) its value ( $Y_{\text {RSmax }}$ of $97 \pm 8 \mathrm{mg} / \mathrm{g}$ for $20.0 \mathrm{~g} / \mathrm{L}$ of xylan). This effect could be caused by different possible phenomena, such as promotor regulation effect; inhibition by the end-product and/
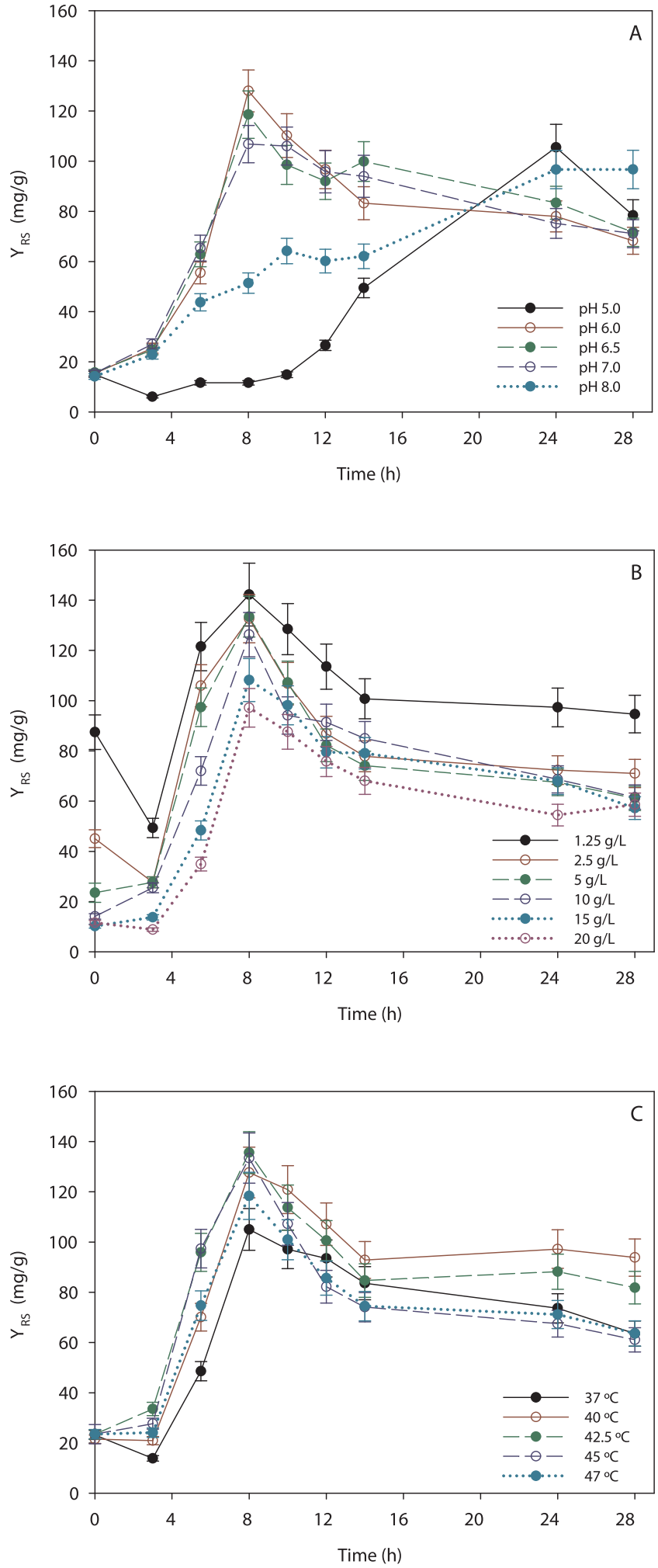

Fig. 2. Sugar production yield $\left(\mathrm{Y}_{\mathrm{RS}}\right)$ obtained for Bacillus subtilis 3610 clone 2 (transformant containing the xylanase gene xyn2 from Trichoderma reesei coupled with a secretion tag endogenous to Bacillus subtilis) in $2 \%(\mathrm{v} / \mathrm{v})$ Vogel media at $950 \mathrm{rpm}$ using: (A) different $\mathrm{pH}(5.0,6.0,6.5,7.0$ and 8.0$)$ at $45^{\circ} \mathrm{C}$ and $10 \mathrm{~g} / \mathrm{L}$ of xylan; (B) different substrate concentration $(1.25,2.5,5.0,10.0,15.0$ and 20) g/L of xylan at $45^{\circ} \mathrm{C}$ and $\mathrm{pH} 6.0$; (C) different temperatures (37, 40, $42.5,45$ and $47^{\circ} \mathrm{C}$ ) at $\mathrm{pH} 6.0$ and $5.0 \mathrm{~g} / \mathrm{L}$ of xylan. 
or substrate; mass transfer and aeration issues (Akpinar, Ak, Kavas, Bakir, \& Yilmaz, 2007; Helianti et al., 2016). The latter is generally associated to the increase of the viscosity and density of the reaction mixture, which occurs when higher concentrations of substrate are present (Akpinar et al., 2007).

A possible effect on promotor regulation caused by the gene manipulation of the microorganism was dismissed as the same negative effect of increasing concentrations of xylan was observed under the same conditions for B. subtilis wt (Appendix A, Fig. A2 in Supplementary material). The hypothesis of inhibition by the end product was tested with the addition of xylose to the original medium containing xylan. As expected, the xylanase activity was residual in this scenario, due to the preferential consumption of free xylose in the media (data not shown). Lastly, the hypothesis of inhibition by the substrate was assessed through the fed-batch production strategy (more detailed information on this is presented in Section 3.2).

In summary, attending the sensitivity limit of both DNS and HPLC techniques, the optimal concentration of xylan selected was $5.0 \mathrm{~g} / \mathrm{L}$, which was used for the subsequent studies.

The effect of temperature on the $\mathrm{Y}_{\mathrm{RS}}$ was evaluated at $\mathrm{pH} 6.0,5.0 \mathrm{~g} /$ $\mathrm{L}$ xylan and $950 \mathrm{rpm}$, using a temperature range from $37^{\circ} \mathrm{C}$ up to $47^{\circ} \mathrm{C}$ (Fig. 2C). The highest $Y_{\text {RSmax }}$ was obtained at $42.5^{\circ} \mathrm{C}(135.6 \pm 8.3 \mathrm{mg} /$ $\mathrm{g})$ after $8 \mathrm{~h}$ of fermentation with a correspondent $Y_{\mathrm{xyl}}$ of $2.5 \pm 0.4 \mathrm{mg} /$ $\mathrm{g}$, while the lowest $\mathrm{Y}_{\mathrm{RSmax}}$ was observed at $37^{\circ} \mathrm{C}(105 \pm 8 \mathrm{mg} / \mathrm{g})$. The optimal temperature possibly stands under the synergy between the optimal temperature for B. subtilis growth, between 30 and $37^{\circ} \mathrm{C}$ (Korsten \& Cook, 1996), the positive effect of high temperatures in reducing xylan viscosity and consequently increasing oxygen and mass transfer, and the optimal temperature for $B$. subtilis xylanase activity, between 50 and $56^{\circ} \mathrm{C}$ (Banka, Guralp, \& Gulari, 2014; Irfan et al., 2016; Milessi et al., 2015) and T. reesei xylanase (xyn2) activity, around $60^{\circ} \mathrm{C}$ (La Grange, Pretorius, \& van Zyl, 1996). However, this positive effect appears to be more significant for direct fermentation of lignocellulosic biomass, since it improves the accessibility of the enzymes to the hemicelluloses (Amorim et al., 2018).

\subsection{Fed-batch production of XOS by B. subtilis clone 2}

As previously demonstrated in Section 3.1.2, higher concentrations of xylan had a negative impact on $\mathrm{Y}_{\mathrm{RS}}$, possibly due to mass transfer issues and xylanase inhibition by the substrate and the product. In this sense, the fed-batch operation mode was seen as a potential production approach to overcome those issues. Two initial concentrations of xylan were tested, 2.5 and $5.0 \mathrm{~g} / \mathrm{L}$, which were increased up to 5.0 and $7.5 \mathrm{~g} /$ $\mathrm{L}$ of total substrate, by one impulse addition of a concentrated xylan solution at different fermentation times (3, 5, 7 and $9 \mathrm{~h}$ ) (Fig. 3A and B). The $\mathrm{pH}$ and temperature conditions previously selected as optimal for batch production (Section 3.1.2) were also used in these experiments, namely $42.5^{\circ} \mathrm{C}$ and $\mathrm{pH}$ 6.0.

For both initial concentrations of xylan, the impulse at $3 \mathrm{~h}$ lead to the highest $\mathrm{Y}_{\mathrm{RSmax}}$, which was achieved after $8 \mathrm{~h}$ of fermentation, similarly to what occurs in the batch operation mode. Nonetheless, only for an initial xylan concentration of $2.5 \mathrm{~g} / \mathrm{L}$, the $\mathrm{Y}_{\mathrm{RS} \max }$ increased significantly (t-student test, $\alpha=0.05$ ), around $12 \%$, when compared to the optimized batch mode $(136 \pm 8 \mathrm{mg} / \mathrm{g})$. The TLC analysis of the fermentation supernatant at $8 \mathrm{~h}$ shows strong bands in the region of 4-, 5- and 6-DP XOS and only a vestigial band can be observed in the xylose region (Appendix A, Fig. A1 in Supplementary material).

A two-time impulse fed-batch was also tested at 3 and $5 \mathrm{~h}$, using an initial xylan concentration of $2.5 \mathrm{~g} / \mathrm{L}(\mathrm{w} / \mathrm{v})$ which was increased to a total of $7.5 \mathrm{~g} / \mathrm{L}$ with the impulses. However, when compared to one impulse, this scenario affected negatively both $\mathrm{Y}_{\mathrm{RS} m a x}$, decreasing $8 \%$, and $t_{\max }$, increasing $3 \mathrm{~h}$ (data not shown), when compared to the batch results, possibly due to substrate inhibition.

The improvement of the $\mathrm{Y}_{\mathrm{RSmax}}$ using the one-time impulse fedbatch corroborates the hypothesis of substrate inhibition, however a
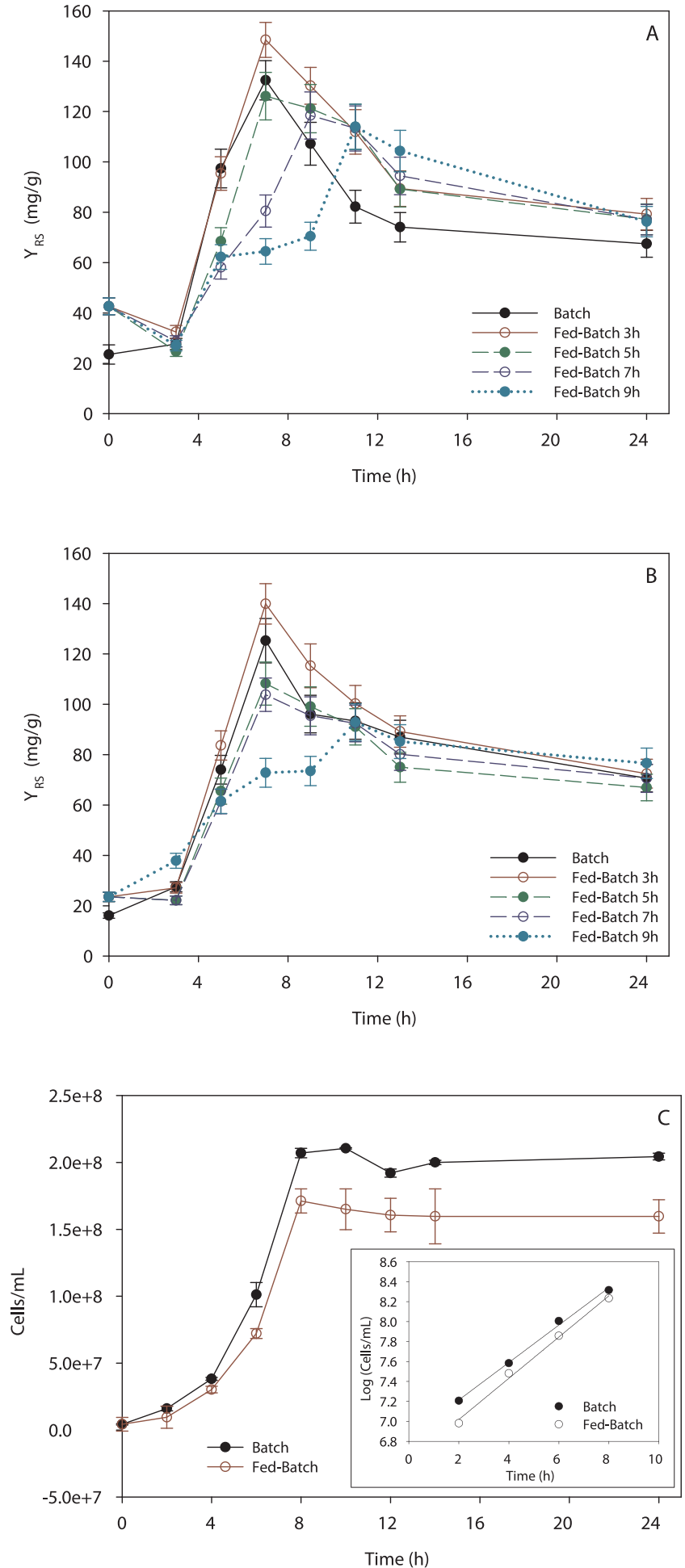

Fig. 3. Sugar production yield ( $\mathrm{Y}_{\mathrm{RS}}$ ) obtained for Bacillus subtilis 3610 clone 2 cultured in $2 \%(\mathrm{v} / \mathrm{v})$ Vogel media by one impulse fed-batch regime at $42.5^{\circ} \mathrm{C}$, $\mathrm{pH} 6.0$ and $950 \mathrm{rpm}$ using an initial xylan concentration of $2.5 \mathrm{~g} / \mathrm{L}$ (A) and $5.0 \mathrm{~g} / \mathrm{L}$ (B), increased up to a total amount of 5.0 and $7.5 \mathrm{~g} / \mathrm{L}$, respectively. (C) Cell concentration obtained for B. subtilis 3610 clone 2 cultured in $2 \%(\mathrm{v} / \mathrm{v})$ Vogel media at $42.5^{\circ} \mathrm{C}$, pH 6.0 and $950 \mathrm{rpm}$ in batch mode and one impulse fedbatch at $3 \mathrm{~h}$ using an initial xylan concentration of $2.5 \mathrm{~g} / \mathrm{L}$ reaching a total amount of xylan of $5.0 \mathrm{~g} / \mathrm{L}$. The fermentations were performed in microbioreactor. Results represent the average of three independent assays \pm standard deviation. 
more detailed study should be performed to evaluate the mechanisms underlying this phenomenon.

Interestingly, the most considerable improvement of $\mathrm{Y}_{\mathrm{RSmax}}$ was due to the genetic engineering of the microorganism, $37 \%$ higher than the wild type, while the process optimization led to a less significant increase of the yield (around 16\%). The optimization of the microorganism performance may represent a key factor to ensure the economic viability of XOS production by direct fermentation. Furthermore, the two-step metabolism of xylan, including the initial production of oligosaccharides followed by their degradation, is one of the main advantages of the direct fermentation approach, since it allows to minimize the amount of free xylose. This fact considerably simplifies the downstream process, which generally represents up to $80 \%$ of the total entire production costs (Urmann, Graalfs, Joehnck, Jacob, \& Frech, 2010).

Fig. 3C shows the biomass growth quantified under the best conditions selected for the batch (Section 3.1.2) and fed-batch fermentation. Interestingly, the batch mode leads to a higher cell density at $8 \mathrm{~h}$ $\left(207 \times 10^{6}\right.$ cells $\left./ \mathrm{mL}\right)$, although presenting a higher doubling time (98 min) when compared to fed-batch $\left(171 \times 10^{6}\right.$ cells $/ \mathrm{mL}$ and $87 \mathrm{~min}$ ). Higher number of cells may imply higher number of xylanases in the medium, as well as xylosidases, also responsible for XOS degradation. Thus, since the production of XOS is growth-associated, the direct fermentation of xylan requires a precise amount of biomass to allow a high production and a slow degradation of XOS, leading to their accumulation in a specific time.

\subsection{Quantification and chemical characterization of XOS produced by $B$. subtilis clone 2}

The amount of XOS produced by B. subtilis clone 2 was quantified by HPLC after their partial purification (Sections 2.6 and 2.7). Table 1 shows the production yields in equivalents of xylose for XOS, $\mathrm{Y}_{\mathrm{XOS}}$, free xylose, $\mathrm{Y}_{\mathrm{Xyl}}$, uptake of xylose, $\mathrm{Y}_{\mathrm{xup}}$, and residual xylan, $\mathrm{Y}_{\mathrm{xr}}$, obtained per gram of xylan after $8 \mathrm{~h}$ of fermentation under fed-batch mode at optimal conditions selected in Section 3.2.

The $Y_{X O S}$ quantified by HPLC (306 $\pm 4 \mathrm{mg} / \mathrm{g}$ ) deviates greatly from $\mathrm{Y}_{\mathrm{RS}}$ obtained by DNS $(148 \pm 10 \mathrm{mg} / \mathrm{g})$. It is important to note that DNS was used previously as a qualitative technique to set the fermentative profile evolution in terms of total reducing sugars (Sections 3.1-3.2). However, it is important to highlight the limitations of this technique for evaluating a mixture of oligosaccharides, since DNS assay can only be accurate for the evaluation of a single reducing sugar (Miller, 1959). Indeed, this technique responds differently to XOS of different DPs, showing lower reactivity to lower-DP XOS (Jeffries, Yang, \& Davis,

Table 1

XOS production yield, Yxos, and process mass balance, including the production yields in equivalents of xylose of: XOS, $Y_{\text {Xos_Xeq, }}$, free xylose, $Y_{x y l}$, uptake of xylose, $Y_{x u p}$, and residual xylan, Yxr, produced at $8 \mathrm{~h}$ from beechwood xylan by direct fermentation with Bacillus subtilis clone 2 under one-time impulse fed-batch $(2.5 \mathrm{~g} / \mathrm{L}$ of initial xylan increased up to $5.0 \mathrm{~g} / \mathrm{L}$ at $3 \mathrm{~h}, \mathrm{pH} 6.0,42.5^{\circ} \mathrm{C}$ and $950 \mathrm{rpm}$ ).

\begin{tabular}{ll}
\hline Product Yield & $\mathrm{mg} / \mathrm{g}$ \\
\hline $\mathrm{Y}_{\mathrm{XOS}}$ & $306 \pm 4$ \\
Xylotetraose & $55.7 \pm 0.9$ \\
Xylopentaose & $145 \pm 1$ \\
Xylohexose & $105 \pm 2$ \\
\hline Process mass balance & $\mathrm{mg} / \mathrm{g}$ \\
\hline $\mathrm{Y}_{\mathrm{XOSXeq}}$ & $348 \pm 4$ \\
$\mathrm{Y}_{\mathrm{Xyl}}$ & $1.3 \pm 0.2$ \\
$\mathrm{Y}_{\mathrm{Xup}}$ & $142 \pm 7$ \\
$\mathrm{Y}_{\mathrm{XR}}$ & $507 \pm 11$
\end{tabular}

Table 2

Free xylose yield, $\mathrm{Y}_{\mathrm{Xyl}}$, and supernatant yield in xylose equivalents, $\mathrm{Y}_{\mathrm{XS}}$, obtained at $8 \mathrm{~h}$ by Bacillus subtilis wild type (wt) and B. subtilis clone 2 (transformant containing the xylanase gene xyn2 from Trichoderma reesei coupled with a secretion tag endogenous to $B$. subtilis) cultured in microbioreactor at $950 \mathrm{rpm}$.

\begin{tabular}{lllll}
\hline & wt $^{(\text {a) }}$ & clone2 $^{\text {(a) }}$ & clone2 $^{\text {(b) }}$ & clone2 $^{\text {(c) }}$ \\
\hline $\mathrm{Y}_{\mathrm{XS}}(\mathrm{mg} / \mathrm{g})$ & $824 \pm 5$ & $944 \pm 7$ & $984 \pm 7$ & $997 \pm 7$ \\
$\mathrm{Y}_{\mathrm{XYL}}(\mathrm{mg} / \mathrm{g})$ & $16 \pm 1$ & $3.5 \pm 0.6$ & $2.5 \pm 0.4$ & $1.3 \pm 0.2$ \\
$\mathrm{Y}_{\mathrm{Xup}}(\mathrm{mg} / \mathrm{g})$ & $301 \pm 6$ & $193 \pm 8$ & $154 \pm 7$ & $142 \pm 7$ \\
\hline
\end{tabular}

(a) Non-optimized batch $\left(10.0 \mathrm{~g} / \mathrm{L}\right.$ of xylan, $\mathrm{pH} 6.0$ and $\left.45^{\circ} \mathrm{C}\right)$.

(b) Optimized batch $\left(5.0 \mathrm{~g} / \mathrm{L}\right.$ of xylan, $\mathrm{pH} 6.0$ and $\left.42.5^{\circ} \mathrm{C}\right)$.

(c) One-time impulse fed-batch $(2.5 \mathrm{~g} / \mathrm{L}$ of initial xylan, impulse of $2.5 \mathrm{~g} / \mathrm{L}$ xylan at $3 \mathrm{~h}, \mathrm{pH} 6.0$ and $42.5^{\circ} \mathrm{C}$ ).

1998), which may explain the differences observed between $Y_{X O S}$ and $\mathrm{Y}_{\mathrm{RS}}$.

The relative amount of $\mathrm{Y}_{\mathrm{XOSXeq}}$ in the mixture at $8 \mathrm{~h}$ was higher than the $Y_{x y l}$ and $Y_{x u p}$ together, however the residual xylan represents the most considerable portion, suggesting that the microorganisms degrades the xylan in a stepwise process. In this sense, a continuous process could be a potential approach to overcome the dynamics of the microorganism metabolism. Nonetheless, it is important to highlight that $\mathrm{Y}_{\mathrm{XR}}$ could be overestimated, as it may be including the XOS with DP $>6$ which cannot be detected by HPLC within the sensitivity limits. This is corroborated by the TLC analysis that presents a blurred band corresponding to the region of DP $>6$ XOS (Appendix A, Fig. A1 in Supplementary material).

Noteworthy, clone 2 presented a reduction of both $\mathrm{Y}_{\mathrm{XYL}}$ and $\mathrm{Y}_{\mathrm{xup}}$ values when compared to the wild type (Table 2). This performance improvement was mostly due to the genetic manipulation of $B$. subtilis, which allowed a reduction in 4- and 2-fold for $\mathrm{Y}_{\mathrm{XYL}}$ and $\mathrm{Y}_{\mathrm{xup}}$, respectively. Similar XOS production yields per gram of xylan using an enzymatic approach has been reported (Azelee et al., 2016; Bian et al., 2013; Kallel et al., 2014). To hydrolyze pretreated sugarcane bagasse using a xylanase of Pichia stipites during $12 \mathrm{~h}, 318.0 \mathrm{mg} / \mathrm{g}$ were obtained (Bian et al., 2013); a yield of $307.4 \mathrm{mg} / \mathrm{g}$ was obtained after an $8 \mathrm{~h}$ hydrolysis of garlic straw xylan with Bacillus mojavensis UEB-FK xylanase (Kallel et al., 2014), and $351.5 \mathrm{mg} / \mathrm{g}$ of XOS were produced from pretreated kenaf stems using an enzymatic cocktail of Xyn2:AnabfA during $48 \mathrm{~h}$ (Azelee et al., 2016). However, these processes require an extra step for the enzyme production (when it is not purchased), which is not being considered in the final yield, increasing significantly the cost of the production process. These constrains highlight the potential of using a single step approach to produce XOS.

Additionally, it is important to refer that the $\mathrm{Y}_{\mathrm{XO}}$ obtained in the present study is lower than the one obtained for BSG $(542 \mathrm{mg} / \mathrm{g}$ ) (Amorim et al., 2018) after $12 \mathrm{~h}$ of fermentation using the same modified microorganism. A possible explanation for this evidence could rely on the complexity of the lignocellulosic biomass in BSG, which may provide other compounds such as sugars and other elements stimulating biomass growth and xylanase activity. Goyal, Kalra, Sareen, and Soni, (2008) reported a higher activity of Trichoderma viride xylanase using lignocellulosic biomass as compared to that with xylan as carbon source. To confirm this evidence, a preliminary study was performed using $T$. reesei for direct fermentation of xylan, resulting in lower xylanase activity values when compared to the use of BSG as carbon source (data not shown). Therefore, the successful use of this single step strategy requires the combination of suitable lignocellulosic materials and effective xylanase producers.

The XOS produced were characterized by GC-MS (Section 2.10). For that purpose, the XOS were previously separated by HPLC (Section 2.9) and individually collected according their DP for neutral sugars analysis and glycosidic linkage analysis (Table 3).

Methylation analysis showed the presence of linear XOS composed 
Table 3

Glycosidic linkage composition (\% mol) of the different XOS produced (A, B, and $\mathrm{C}$ ) after $8 \mathrm{~h}$ of fermentation by Bacillus subtilis clone 2 in one-time impulse fed-batch, using an initial xylan concentration of $2.5 \mathrm{~g} / \mathrm{L}$, increased up to a total amount of $5.0 \mathrm{~g} / \mathrm{L}$ at $3 \mathrm{~h}, \mathrm{pH} 6.0,42.5^{\circ} \mathrm{C}$ and $950 \mathrm{rpm}$.

\begin{tabular}{llll}
\hline & \multicolumn{2}{l}{$\% \mathrm{~mol}$} & \\
\cline { 2 - 4 } Glycosidic linkage composition & $\mathrm{A}$ & $\mathrm{B}$ & $\mathrm{C}$ \\
\hline t-Araf & 2.2 & 1.0 & 1.0 \\
5-Araf & 0.5 & 0.4 & 0.4 \\
Total & 2.7 & 1.4 & 1.3 \\
t-Xylp & 16.4 & 19.7 & 14.1 \\
3-Xylp & 0.2 & 0.2 & 0.2 \\
4-Xylp & 51.3 & 75.9 & 74.6 \\
2,4-Xylp & 0.8 & 0.2 & 0.4 \\
3,4-Xylp & 0.2 & tr & 0.2 \\
2,3,4-Xylp & 1.4 & & 0.7 \\
Total & 70.2 & 96.0 & 90.3 \\
t-Glc & 16.5 & 0.5 & 0.6 \\
3-Glc & & & 0.4 \\
4-Glc & 3.0 & 0.5 & 2.7 \\
2,3,4,6-Glc & 3.2 & 1.6 & 4.5 \\
Total & 22.7 & 2.5 & 8.2 \\
t-Gal & 4.2 & & \\
2,3,4,6-Gal & 0.2 & 0.1 & 0.2 \\
Total & 4.4 & 0.1 & 0.2 \\
XOS degree of polymerization & 4 & 5 & 6 \\
\% Branching & 5.3 & 0.2 & 2.2 \\
\hline
\end{tabular}

mainly of $(1 \rightarrow 4)$-linked-xylopyranosyl residues with a small amount of branched residues. The fraction A contained XOS with an average DP of 4 with $5.3 \%$ of branching, were the branching points are mainly in disubstituted xylose residues with terminally linked arabinofuranose. The presence of glucose $(22.7 \%)$, galactose $(4.4 \%)$, and arabinose $(2.7 \%)$ in fraction A may be explained by the composition of the commercial beechwood xylan (Section 2.1), as this fraction with the lowest DP level analysed (DP $=4$ ) was a minor portion of the all amount of the produced XOS (18\%, Table 1$)$.

Fraction B was almost composed of xylopentaose linear oligosaccharides and fraction $\mathrm{C}$ presented an average degree of polymerization of 6 xylose residues with $2.2 \%$ of branching (Table 3 ).

Interestingly, the DP-pattern obtained with clone 2 (4-6) is more characteristic of $T$. reesei xyn2 activity (Tenkanen et al., 1992) than $B$. subtilis endo-xylanase, which is associated to the production of lower DP XOS (between 2 and 4) (Reddy \& Krishnan, 2016b). These results suggest that there is a dominance of xyn2 activity over the endogenous xylanase system of $B$. subtilis.

To modulate the gut microbiota the prebiotic oligosaccharides must be resistant to digestion in upper gastrointestinal tract, i.e. reaching the large intestine intact (Gibson et al., 2017). The stability of the produced XOS to the digestive system (i.e. gastric acidity, digestive enzymes) was tested under a harmonized static in vitro digestion method. After digestion, $98.5 \pm 0.2 \%$ of the oligosaccharides remained in its complex form, without being degraded. This means the produced XOS were resistant to hydrolysis along the simulated harsh conditions of the gastrointestinal system, suggesting that they could reach the large intestine intact.

\section{Conclusions}

The current study clearly highlights the potential of using genetic engineering tools to improve the performance of $B$. subtilis to produce XOS, a prebiotic functional food ingredient. Cloning T. reesei xylanase gene coupled with a secretion tag into $B$. subtilis wt allowed increasing the production of XOS and reducing the production and uptake of free xylose obtained by direct fermentation of beechwood xylan.

When comparing to the enzymatic process, direct fermentation is a more attractive and advantageous approach to produce XOS, presenting the potential of reducing costs associated with enzymes purchase and downstream process.

\section{Acknowledgments}

CA, SCS, ACP, EC and LRR acknowledge their grants (PD/BD/ 105870/2014, SFRH/BPD/88584/2012, SFRH/BPD/ 101181/2014, SFRH/BPD/70589/2010 and SFRH/BSAB/142873/2018) from Portuguese Foundation for Science and Technology (FCT). The study received financial support from FCT under the scope of the strategic funding of UID/BIO/04469/2013 unit; COMPETE 2020 (POCI-010145-FEDER-006684); QOPNA research Unit (FCT UID/QUI/00062/ 2013), through national founds and where applicable co-financed by the FEDER, within the PT2020 Partnership Agreement; the Project MultiBiorefinery (POCI-01-0145-FEDER-016403); the Project FoSynBio (POCI-01-0145-FEDER-029549) and Lignozymes (POCI-01-0145FEDER-029773). The authors also acknowledge BioTecNorte operation (NORTE-01-0145-FEDER-000004) funded by the European Regional Development Fund under the scope of Norte2020 - Programa Operacional Regional do Norte.

\section{Appendix A. Supplementary data}

Supplementary material related to this article can be found, in the online version, at doi:https://doi.org/10.1016/j.carbpol.2018.09.088.

\section{References}

Aachary, A. A., Gobinath, D., Srinivasan, K., \& Prapulla, S. G. (2015), Protective effect of xylooligosaccharides from corncob on 1,2-dimethylhydrazine induced colon cancer in rats. Bioactive Carbohydrates and Dietary Fibre, 5, 146-152.

Akpinar, O., Ak, O., Kavas, A., Bakir, U., \& Yilmaz, L. (2007). Enzymatic production of xylooligosaccharides from cotton stalks. Journal of Agricultural and Food Chemistry, 55, 5544-5551.

Amorim, C., Silvério, S. C., Silva, S. P., Coelho, E., Coimbra, M. A., Prather, K. L. J., et al. (2018). Single-step production of arabino-xylooligosaccharides by recombinant Bacillus subtilis 3610 cultivated in brewers' spent grain. Carbohydrate Polymers, 199, $546-554$.

Amorim, C., Silvério, S. C., \& Rodrigues, L. R. (2019). One-step process for producing prebiotic arabino-xylooligosaccharides from brewer's spent grain employing Trichoderma species. Food Chemistry, 270, 86-94.

Azelee, N. I. W., Jahim, J., Md, Ismail, A. F., Fuzi, S. F. Z. M., Rahman, R. A., et al. (2016). High xylooligosaccharides (XOS) production from pretreated kenaf stem by enzyme mixture hydrolysis. Industrial Crops and Products, 81, 11-19.

Banka, A. L., Guralp, S. A., \& Gulari, E. (2014). Secretory expression and characterization of two hemicellulases, xylanase, and $\beta$-xylosidase, isolated from Bacillus subtilis M015. Applied Biochemistry and Biotechnology, 174, 2702-2710.

Bian, J., Peng, F., Peng, X.-P., Peng, P., Xu, F., \& Sun, R.-C. (2013). Structural features and antioxidant activity of xylooligosaccharides enzymatically produced from sugarcane bagasse. Bioresource Technolology, 127, 236-241.

Bian, J., Peng, P., Peng, F., Xiao, X., Xu, F., \& Sun, R. C. (2014). Microwave-assisted acid hydrolysis to produce xylooligosaccharides from sugarcane bagasse hemicelluloses. Food Chemistry, 156, 7-13.

Carvalho, A. F. A., Neto, P. O., Silva, D. F., \& Pastore, G. M. (2013). Xylo-oligosaccharides from lignocellulosic materials: Chemical structure, health benefits and production by chemical and enzymatic hydrolysis. Food Research International, 51, 75-85.

Coelho, E., Rocha, M. A. M., Moreira, A. S. P., Domingues, M. R. M., \& Coimbra, M. A. (2016). Revisiting the structural features of arabinoxylans from brewers' spent grain. Carbohydrate Polymers, 139, 167-176.

Courtin, C. M., Swennen, K., Verjans, P., \& Delcour, J. A. (2009). Heat and pH stability of prebiotic arabinoxylooligosaccharides, xylooligosaccharides and fructooligosaccharides. Food Chemistry, 112, 831-837.

Cruz, M. G., Bastos, R., Pinto, M., Ferreira, J. M., Santos, J. F., Wessel, D. F., et al. (2018). Waste mitigation: From an effluent of apple juice concentrate industry to a valuable ingredient for food and feed applications. Journal of Cleaner Production, 193, $652-660$.

Finegold, S. M., Li, Z., Summanen, P. H., Downes, J., Thames, G., Corbett, K., et al. (2014). Xylooligosaccharide increases bifidobacteria but not lactobacilli in human gut microbiota. Food \& Function, 5, 436-445.

Gibson, G. R., Hutkins, R., Sanders, M. E., Prescott, S. L., Reimer, R. A., Salminen, S. J., et al. (2017). The International Scientific Association for Probiotics and Prebiotics (ISAPP) consensus statement on the definition and scope of prebiotics. Nature Reviews Gastroenterology \& Hepatology, 14, 491-502.

Goyal, M., Kalra, K. L., Sareen, V. K., \& Soni, G. (2008). Xylanase production with xylan rich lignocellulosic wastes by a local soil isolate of Trichoderma viride. Brazilian Journal of Microbiology, 39, 535-541.

GVR - Grand View Research Inc (2016). Prebiotics market projected to reach $\$ 7.11$ billion by 
2024. (Accessed 04 2017) https://www.grandviewresearch.com/press-release/ global-prebiotics-market.

Helianti, I., Ulfah, M., Nurhayati, N., Suhendar, D., Finalissari, A. K., \& Wardani, A. K. (2016). Production of xylanase by recombinant Bacillus subtilis DB104 cultivated in agroindustrial waste medium. HAYATI Journal of Biosciences, 23, 125-131.

Hsu, C. K., Liao, J. W., Chung, Y. C., Hsieh, C. P., \& Chan, Y. C. (2004). Xylooligosaccharides and fructooligosaccharides affect the intestinal microbiota and precancerous colonic lesion development in rats. The Journal of Nutrition, 134, $1523-1528$.

Irfan, M., Asghar, U., Nadeem, M., Nelofer, R., \& Syed, Q. (2016). Optimization of process parameters for xylanase production by Bacillus sp. in submerged fermentation. Journal of Radiation Research and Applied Sciences, 9, 139-147.

Jaacks, K. J., Healy, J., Losick, R., \& Grossman, A. (1989). Identification and characterization of genes controlled by the sporulation-regulatory gene spoOH in Bacillus subtilis. American Society for Microbiology, 171, 4121-4129.

Jeffries, T. W., Yang, V. W., \& Davis, M. W. (1998). Comparative study of xylanase kinetics using dinitrosalicylic, arsenomolybdate, and ion chromatographic assays. Applied Biochemistry and Biotechnology, 70-2, 257-265.

Kallel, F., Driss, D., Bouaziz, F., Neifer, M., Ghorbel, R., \& Chaabounia, S. E. (2014). Production of xylooligosaccharides from garlic straw xylan by purified xylanase from Bacillus mojavensis UEB-FK and their in vitro evaluation as prebiotics. Food and Bioproducts Processing, 94, 536-546.

Kaprelyants, L., Zhurlova, O., Shpyrko, T., \& Pozhitkova, L. (2017). Xylooligosaccharides from agricultural by-products: characterisation, production and physiological effects. Food Science and Technology, 11, 25-34.

Korsten, L., \& Cook, N. (1996). Optimizing culturing conditions for Bacillus subtilis. South African Avocado Growers' Association Yearbook, 19, 54-58.

La Grange, D. L. C., Pretorius, I. S., \& van Zyl, W. H. (1996). Expression of a Trichoderma reesei b-xylanase gene (XYN2) in Saccharomyces cerevisiae. Applied and Environmental Microbiology, 62, 1036-1044.

Maurelli, L., Ionata, E., La Cara, F., \& Morana, A. (2013). Chestnut shell as unexploited source of fermentable sugars: effect of different pretreatment methods on enzymatic saccharification. Applied Biochemistry and Biotechnology, 170, 1104-1118.

Milessi, T. S. S., Kopp, W., Rojas, M. J., Manrich, A., Baptista-Neto, A., Tardioli, P. W., et al. (2015). Immobilization and stabilization of an endoxylanase from Bacillus subtilis (XynA) for xylooligosaccharides (XOs) production. Catalysis Today, 259, 130-139.

Miller, G. L. (1959). Use of dinitrosalicylic acid reagent for determination of reducing sugar. Analytical Chemistry, 31, 426-428.

Minekus, M., Alminger, M., Alvito, P., Balance, S., Bohn, T., Bourlieu, C., et al. (2014). A standardised static in vitro digestion method suitable for food - an international consensus. Food \& Function, 5, 1113-1124.

Reddy, S. S., \& Krishnan, C. (2016a). Production of high-pure xylooligosaccharides from sugarcane bagasse using crude $\beta$-xylosidase-free xylanase of Bacillus subtilis KCX006 and their bifidogenic function. LWT - Food Science and Technology, 65, 237-245.

Reddy, S. S., \& Krishnan, C. (2016b). Production of xylooligosaccharides in SSF by Bacillus subtilis KCX006 producing $\beta$-xylosidase-free endo-xylanase and multiple xylan debranching enzymes. Preparative Biochemistry \& Biotechnology, 46, 49-55.

Rycroft, C. E., Jones, M. R., Gibson, G. R., \& Rastall, R. A. (2001). A comparative in vitro evaluation of the fermentation properties of prebiotic oligosaccharides. Journal of Applied Microbiology, 91, 878-887.

Samanta, A. K., Jayapal, N., Kolte, A. P., Senani, S., Sridhar, M., Suresh, K. P., et al. (2012). Enzymatic production of xylooligosaccharides from alkali solubilized xylan of natural grass (Sehima nervosum). Bioresource Technology, 112, 199-205.

Tenkanen, M., Puls, J., \& Potanen, K. (1992). Two major xylanases of Trichoderma reesei. Enzyme and Microbial Technology, 14, 566-574.

Urmann, M., Graalfs, H., Joehnck, M., Jacob, L. R., \& Frech, C. (2010). Cation-exchange chromatography of monoclonal antibodies: Characterization of a novel stationary phase designed for production-scale purification. MAbs, 2, 395-404.

Van Zyl, W. H., den Haan, R., \& la Grange, D. C. (2013). Developing cellulolytic organisms for consolidated bioprocessing of lignocellulosics. In K. Gupta, \& M. G. Tuohy (Eds.). Biofuel technologies recent developments (pp. 189-211). Berlin: Springer.

Vogel, H. J. (1956). A convenient growth medium for Neurospora crassa. Microbial Genetics Bulletin, 13, 42-47. 